\title{
An Experimental Trial for Prevention of Necrotic Enteritis by Vaccination and Immune Enhancement of Broiler Chickens
}

\author{
Sarah S. Helal ${ }^{1}$, Hagar F.Gouda ${ }^{2}$, Noura M. khalaf ${ }^{3}$, Rehab I. Hamed ${ }^{4}$, Abd Elmoneim A. Ali ${ }^{5}$ and Mohammed A.Lebdah ${ }^{1}$ \\ ${ }^{1}$ Avian and Rabbit Medicine Department, Faculty of Veterinary Medicine, Zagazig University, 44511, Zagazig, Sharkia Governorate, Egypt. \\ ${ }^{2}$ Animal Wealth Development Department (Biostatistics), Faculty of Veterinary Medicine, Zagazig University, 44511, Zagazig, Sharkia Governorate, Egypt. \\ ${ }^{3}$ Veterinary Serum and Vaccine Research Institute, 11381, Abbassia, Cairo, Egypt \\ ${ }^{4}$ Reference Laboratory for Quality Control on Poultry Production (RLQP), Animal Health Research Institute (Sharkia Branch), Zagazig, Sharkia Governorate, Egypt. \\ ${ }^{5}$ Pathology Department, Faculty of Veterinary Medicine, Zagazig University, 44511, Zagazig , Sharkia Governorate, Egypt
}

"Corresponding author’s Email: dr.sarah.saied@ gmail.com; ORCID: 0000-0003-3047-2239

Received: 23 Feb. 2020

Accepted: 30 Mar. 2020

\begin{abstract}
Alternative strategies are applied for the prevention of Necrotic Enteritis (NE) particularly after the global perspective of the antibiotic ban. This study was a trial for NE control depending on vaccination by toxoid and/or immune enhancement by Nutri-lac IGA administration (a liquid mixture of fermentation by-product $80 \%$, lactic acid $10 \%$, and formic acid 10\%). A total of 120 one-day-old broiler chicks were randomly divided into four groups (30 chicks/group). Group 1 (G1) was vaccinated with $C$. perfringens type A toxoid; Group 2 (G2) was toxoid-vaccinated and immune enhanced by Nutri-Lac IGA; Group 3 (G3) was immune enhanced by Nutri-Lac IGA and Group 4 served as control. Each group was subdivided into two subgroups, one subgroup was challenged with $C$. perfringens and the other was kept unchallenged. No significant clinical signs were detected in birds and mortality was observed only among challenged controls. The thin and friable intestinal wall was observed in all challenged broilers which extended to ulceration only in the challenged control group. No prominent histopathological findings related to NE were detected except in challenged controls and the highest protection against the NE-histopathological changes vividly appeared in the challenged G2 group. Significant increase in body weight of G1 and G2 groups after challenge in comparison to before challenge. While body weight of chickens in both G3 and challenged control groups was lower after challenge than before challenge. Pre-challenge ELISA results indicated no significant difference in immunoglobulin (Ig) Y titer among all groups after the first dose of vaccination, while significant differences appeared after the booster dose. The highest IgY titer was recorded in the G2 group, followed by G1, and G3 group. Post-challenge ELISA results showed a highly significant difference among all challenged subgroups. The highest IgY titer was recorded in the G1, followed by G2, and G3 group. The serum neutralization test also demonstrated the highest mean antibody titer in G1 and G2 groups. In conclusion, this study confirmed that a toxoidimmunostimulant combination is effective in NE prevention only when it is accompanied by the absence of NE predisposing factors.
\end{abstract}

Key words: Broiler chickens, Clostridium perfringens type A, Immunoglobulin Y, Lesion scoring, Necrotic enteritis, Toxoid.

\section{INTRODUCTION}

The poultry industry is one of the most vital sectors of the agriculture production system (Vaarst et al., 2015). Broiler chickens can be grown in an efficient and profitable breeding way by better management and adequate knowledge about infectious poultry diseases despite the continuous risk of developing diseases especially derived from normally inhabited microorganisms in the birds' gut (Timbermont et al., 2011).

Enteric diseases can be caused by a wide range of etiological agents including Clostridium spp. (Cooper et al., 2013). Among clostridial diseases, Necrotic Enteritis
(NE) is considered one of the most threatening diseases in the poultry industry as it is associated with dramatic economic losses mainly due to high mortalities and reduced growth performance (Lovland and Kaldhusdal, 2001; Skinner et al., 2010). NE is principally caused by Clostridium perfringens type A and rarely by type C (Keyburn et al., 2008; Van Immerseel et al., 2009; Shojadoost et al., 2012).

The disease was previously controlled by the administration of antibiotic growth promoters (Lanckriet et al., 2010a), before the ban of antibiotics usage in poultry breeding by European Union (Casewell et al., 2003). There is an emerging need for NE alternative control 
strategies particularly after problems related to the spread of antibiotic-resistant microorganisms and antibiotic residues have appeared. The use of feed additives such as organic acids, essential oils, probiotics, prebiotics and symbiotics can partially decrease the NE occurrence in broilers without complete disease control (Timbermont et al., 2010; Jerzsele et al., 2012).

Recently, several studies have been focused on the development of vaccines against $\mathrm{NE}$ as active supernatants, formalin-inactivated toxoids and modified toxins either in $\mathrm{I} / \mathrm{M}$ or $\mathrm{S} / \mathrm{C}$ administration, in single or multiple dosage vaccination programs (Mot et al., 2013; 2014).

This study was designed to prepare a formalizedkilled vaccine (toxoid) from previously isolated toxigenic $C$. perfringens strain and to evaluate the efficacy of vaccine administration, Nutri-lac IGA treatment or the combination of both in NE controlling by using histopathology and measurement of humoral immune responses.

\section{MATERIALS \& METHODS}

\section{Ethical approval}

All animal care and experimental procedures were reviewed and approved by Zagazig University Institutional Animal Care and Use Committee (IACUC), and the IACUC gave this research the international criteria of the research ethics under the number (ZUIACUC/2/F/102/2019).

\section{Toxoid preparation and evaluation}

The toxoid was prepared according to the method described by Gadalla et al. (1974) using C.perfringens type A highly toxigenic strain, fully identified by conventional and molecular methods by Helal et al. (2019). Thimerosal 10\% (Sigma) was added as preservative and bactericidal agent. Aluminum hydroxide adsorbent gel $2 \%$ (Alliance Bio) was added at a concentration of $20 \%$ as an adjuvant.

The prepared toxoid was tested by sterility and safety tests which were carried out under the regulation of British Veterinary Pharmacopoeia (2007) and ensured that the prepared toxoid was free from any bacterial or fungal contamination and safe for animal use.

\section{Experimental design}

120 one-day-old broiler chicks were obtained from Al Dakahlia Company, Mitghamr County, Dakahlia Governorate, Egypt, floor- reared and fed commercial balanced ration without feed additives. The broilers were randomly divided into four groups (30 chicks/group): Group A was vaccinated; Group B was vaccinated and immune enhanced by Nutri-Lac IGA; Group C was immune enhanced by Nutri-Lac IGA and Group D was kept as control as shown in Table 1.

\section{Toxoid and immunostimulant administration regimen \\ $1^{\text {st }}$ dose of vaccination: S/C injection of broiler} chickens with $0.5 \mathrm{ml}$ of prepared toxoid at 7 days of age. $2^{\text {nd }}$ dose of vaccination (booster dose): $S / C$ injection of broiler chickens with $0.5 \mathrm{ml}$ of prepared toxoid at 21 days of age. Nutri-Lac IGA liquid (Nutriad, Turnhout, Belgium), a liquid mixture of fermentation byproduct $80 \%$, lactic acid $10 \%$ and formic acid $10 \%$, was given to broilers as immunostimulant at dose $3 \mathrm{ml} / 1$ liter drinking water for five successive days at the $1^{\text {st }}$ week of age and repeated at the $3^{\text {rd }}$ week of age for 3-5 days according to the instruction of manufactured company.

\section{Experimental challenge}

Before the experimental challenge, each group was subdivided into 2 subgroups (15 broilers/subgroup). One subgroup was challenged with C.perfringens whole culture and the other subgroup remained without challenge (Control) as shown in table 1.

The challenge was carried out by oral administration of 1-2 $\mathrm{ml}$ of freshly prepared toxigenic NetB-negative C.perfringens whole culture (with bacterial concentration: $10^{9} \mathrm{CFU} / \mathrm{ml}$ and preformed toxin with Minimal Lethal Dose (MLD): $1 / 80)$ for 3 successive days $\left(28^{\text {th }}, 29^{\text {th }}\right.$, and $30^{\text {th }}$ day of broilers`age). Mortalities and clinical signs were recorded during the experimental study.

The mean body weight of all eight groups was measured twice before and after the experimental challenge comparing challenged birds and unchallenged controls. Blood samples were collected four times for measurement of anti-alpha toxin IgY: $1^{\text {st }}$ time: before the $1^{\text {st }}$ dose of vaccination at $7^{\text {th }}$ day of broilers age; $2^{\text {nd }}$ time: after the $1^{\text {st }}$ dose of vaccination at $21^{\text {st }}$ day of broilers` age; $3^{\text {rd }}$ time: after the booster dose of vaccination at $28^{\text {th }}$ day of broilers`age and the last time: after the booster dose of vaccination and experimental challenge at $35^{\text {th }}$ day of broilers`age. Humeral immune response was measured by ELISA according to the method described by Wood (1991) and Serum Neutralization Test (SNT) according to the method described by European pharmacopeia (1997). Lesion scoring was assessed according to the method described by Prescott et al. (1978). Lesions were scored from 0 to 4 (0: No apparent lesion; 1: thin friable small 
intestine; 2: focal necrosis/ulceration or both; 3: patchy necrosis and 4: severe extensive mucosal necrosis). Tissue samples were taken at 7 days post-challenge from all groups either challenged or unchallenged. Tissue sections were routinely stained with $\mathrm{H} \& \mathrm{E}$ and microscopically underwent for histopathological examination.

\section{Statistical analysis}

Data were statistically analyzed by SPSS version 24 (IBM Corp, Armonk, NY). Results were expressed as mean \pm SE. One-way ANOVA was used to test differences among body weights and differences in anti-alpha toxin titer. $P<0.05$ was considered statistically significant. Duncan's multiple range test and least significant difference tests were applied as post hock test after significant ANOVA results. Paired samples t-test was used to test differences between groups before and after administration of toxoid and/or Nutri-lac IGA.

\section{RESULTS}

No marked clinical signs could be detected during this study in all subgroups either in challenged or nonchallenged broilers. No mortalities could be recorded except in the positive control at which 3 out of 15 broiler chickens died at 4th and 5th day post-infection (20\%).

\section{Lesion scoring}

No apparent lesion could be detected in all unchallenged subgroups. Lesion score was 0 in vaccinated, vaccinated and Nutrilac IGA-treated, Nutrilac IGAtreated, and negative controls. Slight congestion in the liver could be seen in all controls. Thinning and friability of intestinal wall could be appeared in challenged vaccinated, vaccinated \& Nutrilac IGA-treated and Nutrilac IGA-treated subgroups (lesion score $=1$ ). Besides, ballooning of intestine, congested mucosa at some intestinal parts and congested liver could be also detected in all challenged subgroups. Positive control showed gross lesions varying from thin and friable intestinal wall (lesion score $=1$ ) to necrosis and/or ulceration in the intestinal mucosa (lesion score $=2$ ). Severely congested liver with or without necrosis and congested intestinal wall with ballooning could be also detected.

\section{Histopathological examination}

In vaccinated challenged subgroup: Focal necrotic intestinal mucosa with few inflammatory cells and the surrounding intestinal crypts were hyperplastic to replace and regenerate the destructed mucosa. Portal mononuclear cell aggregation, congested blood vessels with apparently normal adjacent hepatic cells and hyperplastic Kupffer cells were common in liver (Figure 1). In vaccinated control: Intestinal mucosa and submucosa revealed lymphocytic cell aggregation with the fusion of some intestinal villi, In addition to the presence of mild villous enterocyte desquamation. Mild interstitial and portal lymphocytic aggregation within apparently normal hepatic parenchyma was seen in liver (Figure 1). In vaccinated \& Nutrilac IGA-treated challenged subgroup: Partial desquamated superficial villous enterocytes with the fusion of some intestinal villi, intense inflammatory cells infiltration in mucosa and submucosa and hyperplastic intestinal crypts were noticed. Intense heterophilic aggregation, congested blood vessels and proliferative bile ductules beside normal adjacent hepatic cells were evident in liver (Figure 2). In vaccinated \& Nutrilac IGA-treated control subgroup: Intestinal mucosa showed normal villi lined with enterocytes with proliferative intestinal crypts and normal muscular coat. Mild dilated hepatic sinusoids, normal hepatic cells, hyperplastic Kupffer cells, and few portal lymphocytic infiltrations were common in liver (Figure 2). In Nutrilac IGA-treated challenged subgroup: Mild intestinal lesions represented by partial destruction and desquamation of villous epithelium which resulted in denuded villi. Other villi appeared broad with hyperplastic villous enterocytes from the proliferative intestinal crypts. Focal replacement of the hepatic parenchyma with leukocytic aggregation mainly heterophiles and lymphocytes. The adjacent hepatic parenchyma containing hyperplastic Kupffer cells were seen in liver (Figure 3). In the Nutrilac IGA-treated control subgroup: All the intestinal coats appeared normal with proliferative submucosal intestinal crypts. Mild portal lymphocytic and heterophilic infiltration with edematous portal vein wall and normal hepatic cells were noticed in the liver (Figure 3). In positive control subgroup: Diffuse coagulative necrosis containing bacterial colonies and inflammatory cells in the superficial mucosa sometimes with extension to the deeper mucosa. In addition to necrotic debris and inflammatory cells in the lumen were common. The adjacent intestinal crypts in the mucosa and submucosa were necrotic with edema and necrosis of the muscular coat in the intestine. Multiple necrotic areas were disseminated in the hepatic parenchyma with variable degenerative changes in the adjacent hepatic cells. Numerous heterophils were seen in the interstitial tissue and portal area (Figure 4). In the negative control subgroup, all the intestinal coats appeared within the 
normal morphological picture while the hepatic parenchyma appeared normal (Figure 4).

\section{Average body weight}

The difference in body weight (BW) among different subgroups was statistically insignificant $(\mathrm{P}>0.05)$ before the experimental challenge but there was a highly statistical difference in BW of all birds after experimental challenge as shown in Figure 5. Paired samples t-test results indicated that the highest increase in BW was detected in the vaccinated challenged subgroup as the average BW of examined broilers was significantly higher after challenge $(1994.00 \pm 66.69)$ than before $(1460.00 \pm$ 50.99) $\mathrm{P}<0.01$. Also in the vaccinated \& Nutrilac IGAtreated subgroup, the significant difference before and after the challenge was recorded as average BW was higher after challenge $(1566.00 \pm 84.79)$ than before $(1290.00 \pm 30.98) \mathrm{P}<0.05$.

There was a decrease in BW of broiler chickens in the Nutrilac IGA-treated subgroup before and after challenge (1430.00 \pm 66.33 and 1334.00 \pm 100.72$)$, respectively. The same result was detected in the positive

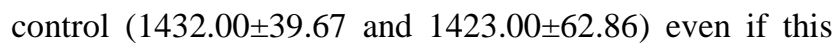
decrease was statistically insignificant $(\mathrm{P}>0.05)$ Figure 5. Significant increase in BW among all unchallenged birds (vaccinated \& Nutrilac IGA-treated $(\mathrm{P}<0.01)$, Nutrilac IGA-treated and negative control $(\mathrm{P}<0.05)$ and vaccinated broilers $(\mathrm{P}>0.05)$ even if this increase was statistically neglected in the last subgroup) (Figure 5).

\section{Humeral immune response before challenge}

One-Way ANOVA results showed that there was a nonsignificant difference among the four groups in ELISA readings after the administration of $1^{\text {st }}$ dose of vaccination at the $7^{\text {th }}$ day and $21^{\text {st }}$ day of broilers' age $(\mathrm{P}>0.05)$ as shown in Figure 6. One-Way ANOVA results showed that there was a highly significant difference among the four groups in ELISA readings after the $2^{\text {nd }}$ dose of vaccination at the $28^{\text {th }}$ day of broilers age. The highest antibody titer was recorded in vaccinated and Nutrilac IGA-treated group $(2.95 \pm 0.21)$ followed by the vaccinated group $(2.55 \pm 0.21)$. Nutrilac IGA-treated group had antibody titer lower $(2.32 \pm 0.20)$ than vaccinated \& Nutrilac IGA-treated group and the small decrease than the vaccinated group was not great to be significant. The negative control had the lowest antibody titer $(1.64 \pm 0.11)$ as shown in Figure 6 . One-Way ANOVA results showed that there was a nonsignificant difference among the unchallenged subgroups in ELISA readings after the $2^{\text {nd }}$ dose of vaccination on the $35^{\text {th }}$ day of broilers age $(\mathrm{P}>0.05)$ as shown in Figure 6.

\section{Humeral immune response after challenge}

One-Way ANOVA results showed that there was a highly significant difference among all subgroups in ELISA readings after the experimental challenge on the $35^{\text {th }}$ day of broilers age as shown in Figure 7 . The highest IgY titer was reported at vaccinated subgroups either challenged $\left(3.64 \pm 0.06^{\mathrm{a}}\right)$ or not $\left(3.66 \pm 0.21^{\mathrm{a}}\right)$. Also vaccinated \& Nutrilac IGA-treated challenged birds had higher IgY titer $\left(2.69 \pm 0.03^{\mathrm{c}}\right)$ more than unvaccinated challenged birds either Nutrilac IGA-treated $\left(2.38 \pm 0.18^{\mathrm{cd}}\right)$ or positive control $\left(2.10 \pm 0.11^{\mathrm{d}}\right)$. Positive control had the lowest antibody titer $\left(2.10 \pm 0.11^{\mathrm{d}}\right)$. It also had a lower antibody titer than challenged Nutrilac IGA-treated group $\left(2.38 \pm 0.18^{\mathrm{cd}}\right)$ but this difference wasn't great to be significant. Negative control nearly had the same antibody titer $\left(3.18 \pm 0.11^{\mathrm{b}}\right)$ of the unchallenged Nutrilac IGA-treated subgroup $\left(3.17 \pm 0.25^{\mathrm{b}}\right)$. SNT results showed variation in the mean antibody titer among different groups as shown in table 2.

Table 1. Experimental design

\begin{tabular}{|c|c|c|c|c|}
\hline Group & Subgroup & Vaccination & Immunostimulant & Experimental challenge \\
\hline \multirow{2}{*}{ Group A } & 1 & + & - & + \\
\hline & 2 & + & - & - \\
\hline \multirow{2}{*}{ Group B } & 3 & + & + & + \\
\hline & 4 & + & + & - \\
\hline \multirow{2}{*}{ Group C } & 5 & - & + & + \\
\hline & 6 & - & + & - \\
\hline \multirow{2}{*}{ Group D } & 7 (positive control) & - & - & + \\
\hline & 8 (negative control) & - & - & - \\
\hline
\end{tabular}


Table 2. Mean anti-alpha toxin titer (IU/ml) in all experimental chicken groups using serum neutralization test.

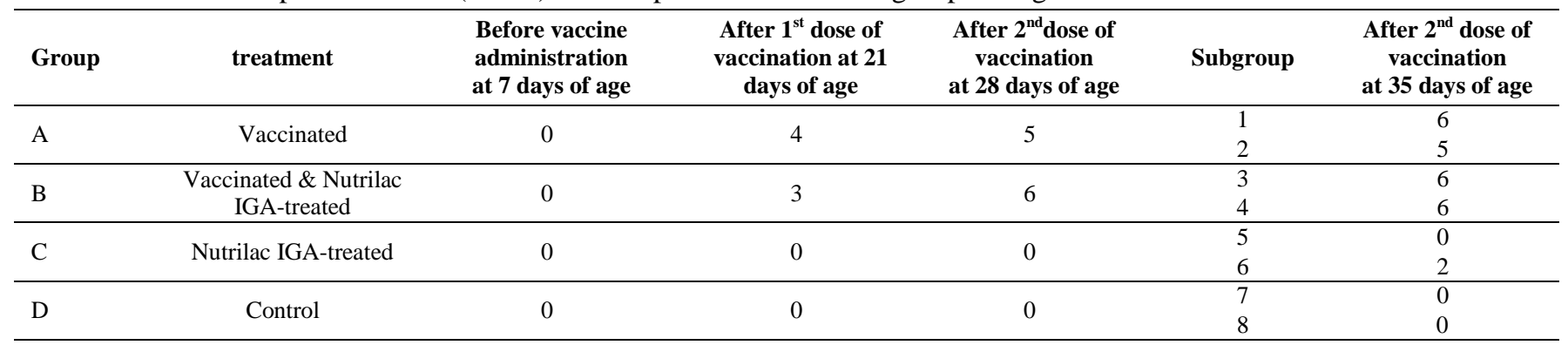

Subgroups 1,3,5 and 7: challenged Subgroups 2,4,6 and 8: unchallenged
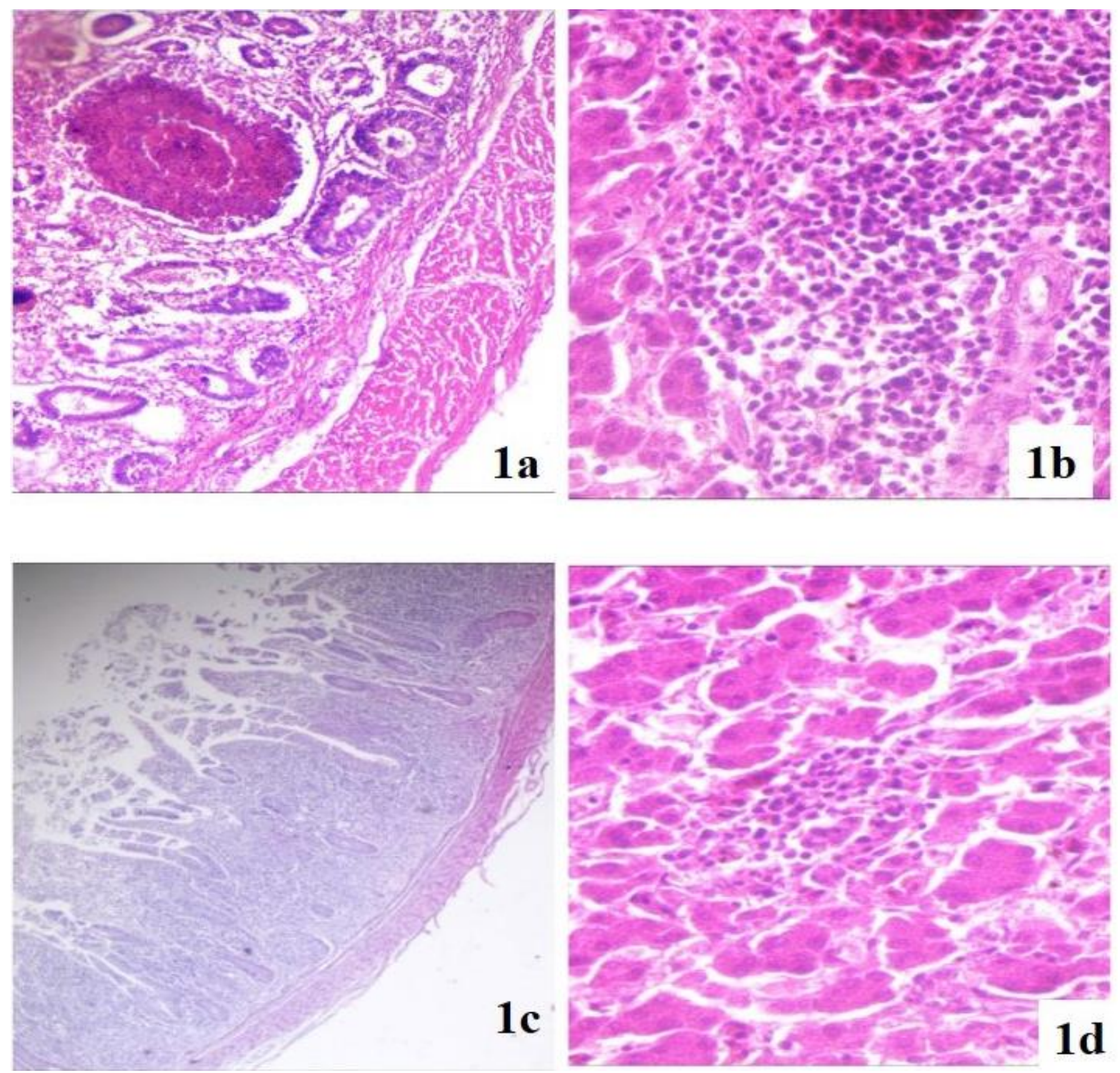

Figure 1. Histopathological examination of liver and intestine of chickens vaccinated with Clostridium perfringens type A toxoid in challenged or unchallenged groups with toxigenic $C$. perfringens culture. (1a) the intestine of vaccinated and challenged chicken showing focal necrosis, few inflammatory cells and hyperplastic intestinal crypts, (1b) liver of vaccinated and challenged chicken showing portal mononuclear cell aggregation, congested blood vessels, apparently normal adjacent hepatic cells and hyperplastic Kuepfer cells, (1c) Intestine of vaccinated and unchallenged chicken showing intense mucosal and submucosal lymphocytic cell aggregation and mild villous enterocyte desquamation, (1d) liver of vaccinated and unchallenged chicken showing mild portal and interstitial lymphocytic aggregation within apparently normal adjacent hepatic parenchyma. $(\mathrm{H} \& \mathrm{E} \times 400)$ 

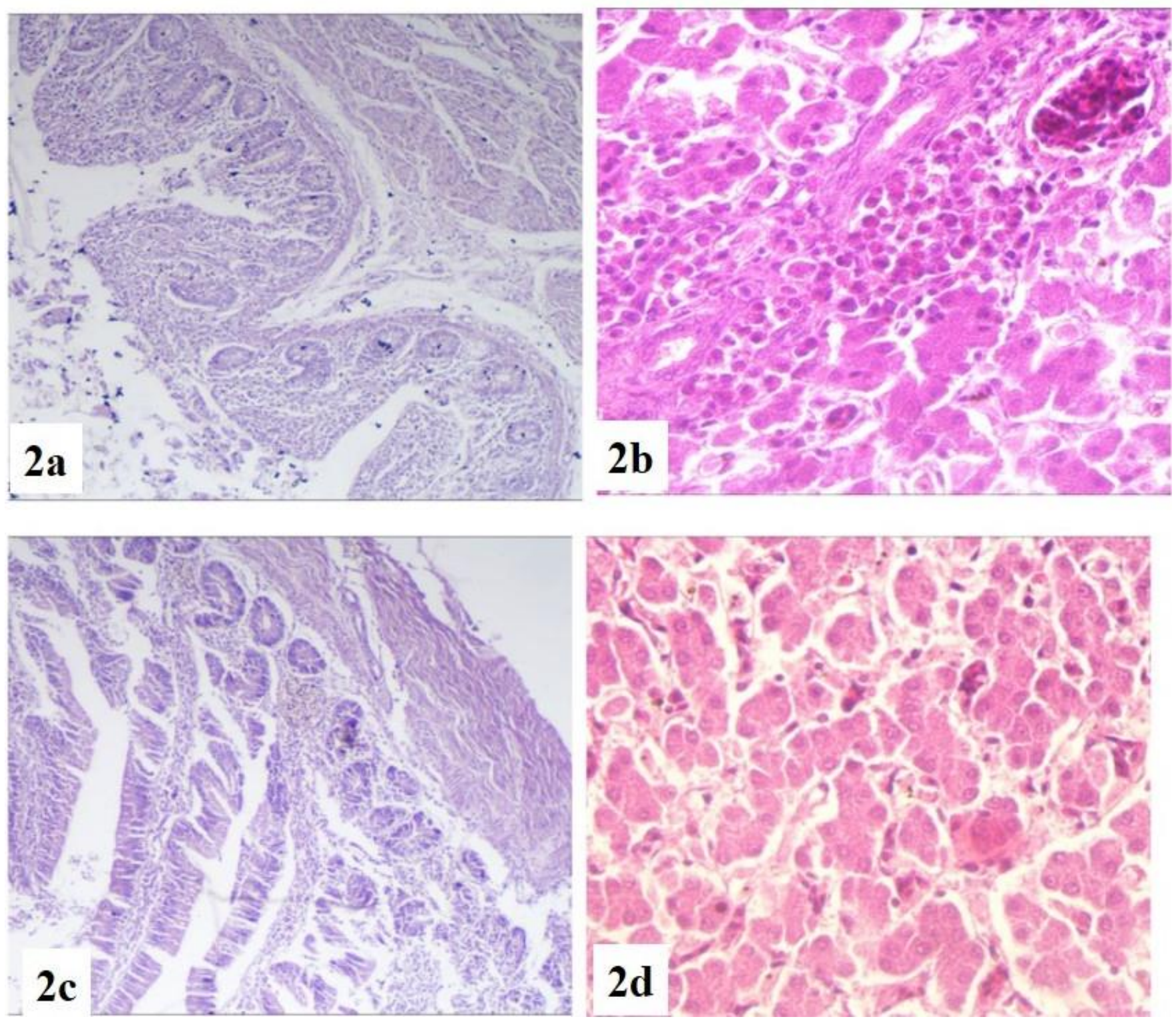

Figure 2. Histopathological examination of intestine and liver of Clostridium perfringens type A toxoid-vaccinated and Nutrilac IGA-treated chickens in challenged or unchallenged groups with toxigenic $C$. perfringens culture. (2a) intestine of vaccinated, Nutrilac IGA-treated (challenged) chicken showing partial desquamated enterocytes, intense infiltrated inflammatory cells and hyperplastic intestinal crypts, (2b) liver of vaccinated, Nutrilac IGA-treated (challenged) chicken showing intense heterophilic aggregation, congested blood vessels and proliferative bile ductules in portal area, (2c) Intestine of vaccinated and Nutrilac IGA-treated (unchallenged) chicken showing normal villi lined with enterocytes, proliferative intestinal crypts, and normal muscular coat, (2d) liver of vaccinated and Nutrilac IGA-treated (unchallenged) chicken showing mild dilated hepatic sinusoids, normal hepatic cells and hyperplastic Kuepfer cells. (H\&E ×400) 

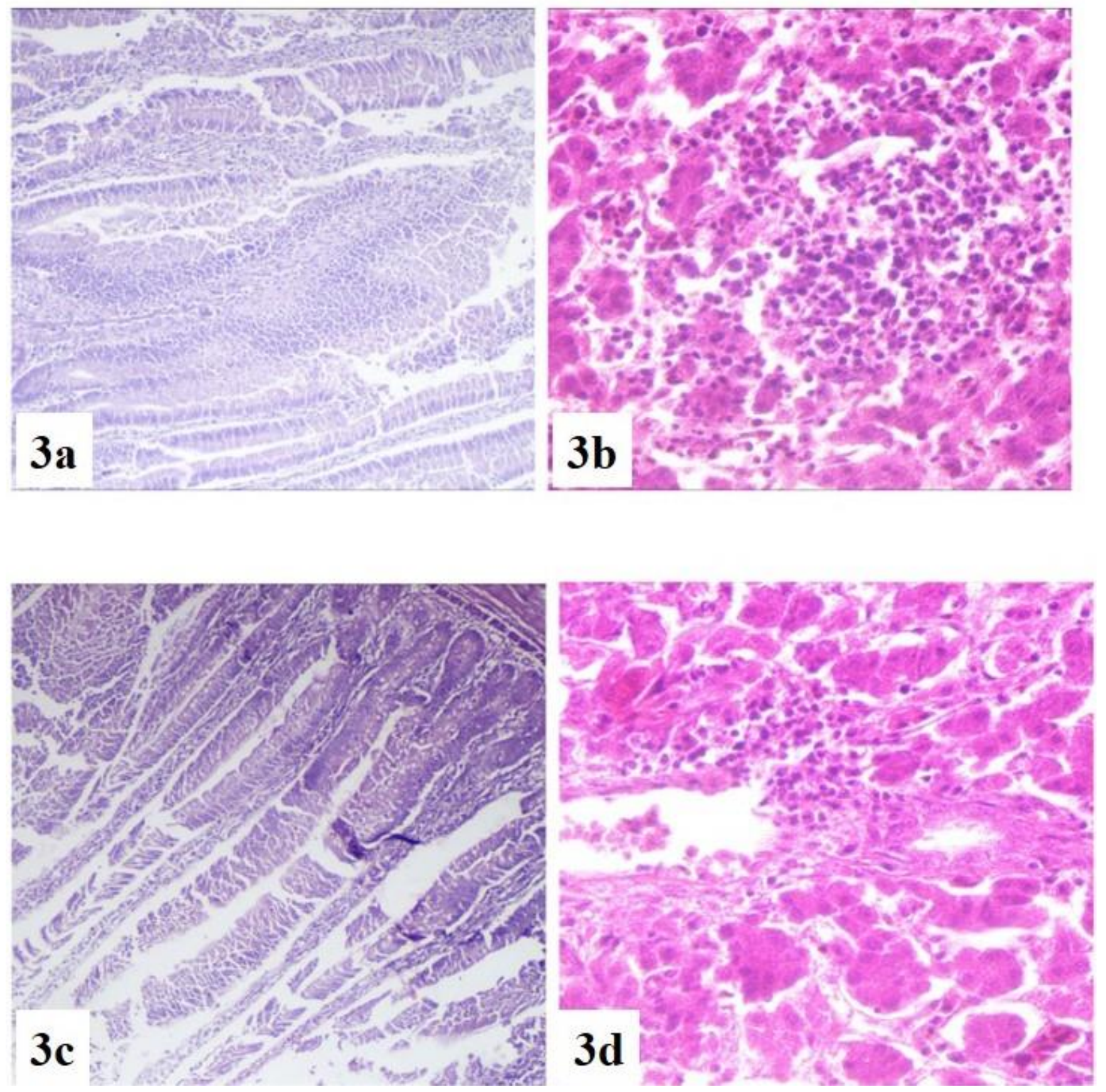

Figure 3. Histopathological examination of intestine and liver of Nutrilac IGA-treated chickens in challenged or unchallenged groups with toxigenic Clostridium perfringens culture. (3a) intestine of Nutrilac IGA-treated chicken (challenged) showing partial destruction and desquamation of villous epithelium which resulted in denuded villi, (3b) liver of Nutrilac IGA-treated chicken (challenged) showing focal replacement of the hepatic parenchyma with leukocyte aggregation mainly heterophiles and lymphocytes, (3c) Intestine of Nutrilac IGA-treated chicken (unchallenged) showing normal intestinal coats with proliferative submucosal intestinal crypts, (3d) liver of Nutrilac IGA-treated chicken (unchallenged) showing mild portal lymphocytes and heterophiles infiltration with edema in the portal vein and normal hepatic cells. $(\mathrm{H} \& \mathrm{E} \times 400)$ 

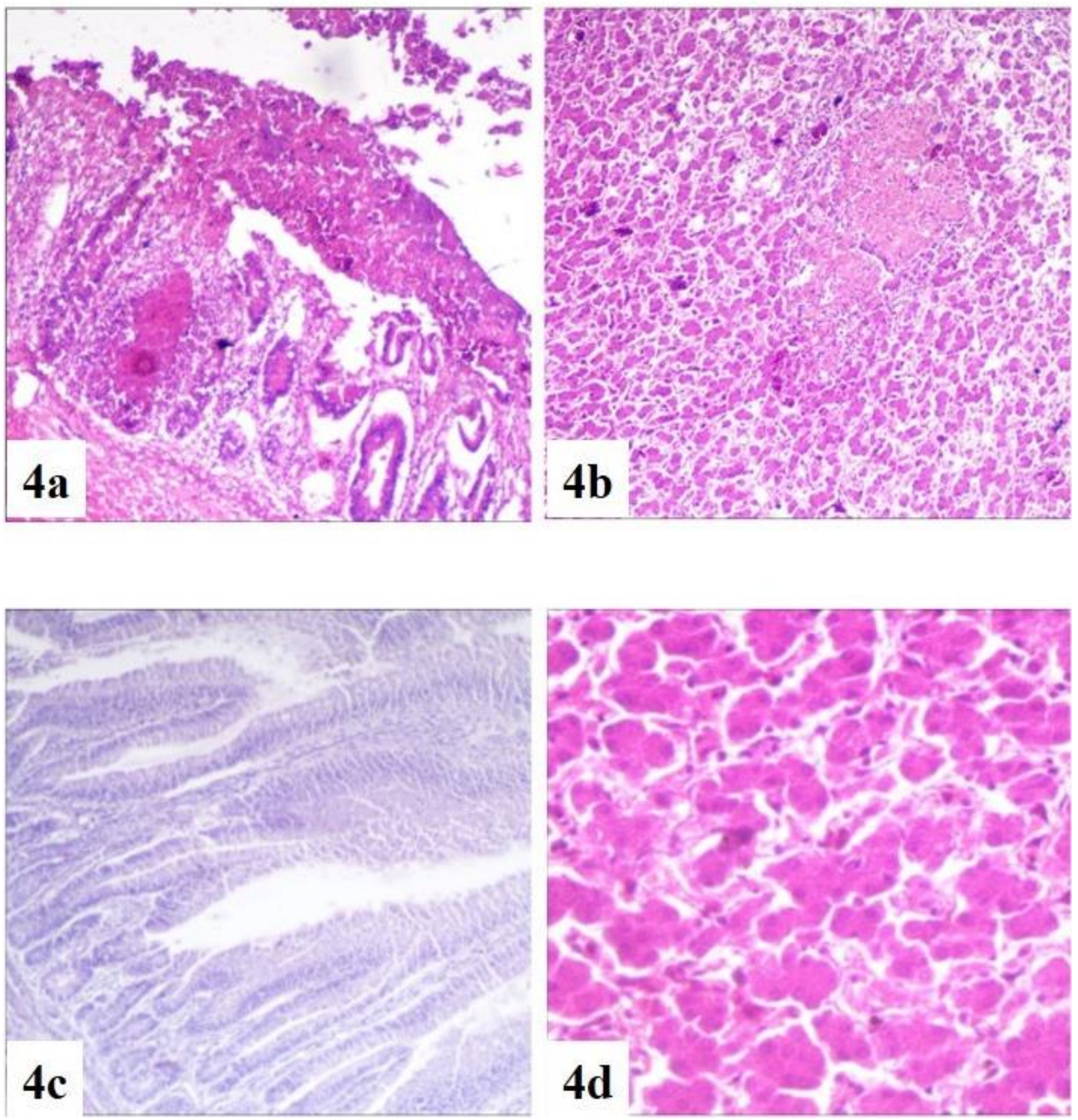

Figure 4. Histopathological examination of liver and intestine of unvaccinated and untreated chickens in challenged or unchallenged groups with toxigenic Clostridium perfringens culture. (4a) intestine of positive control (challenged) chicken showing diffuse coagulative necrosis containing bacterial colonies, inflammatory cells in the superficial mucosa and necrotic intestinal crypts, (4b) liver of positive control (challenged) chicken showing multiple necrotic areas disseminated in the hepatic parenchyma with variable degenerative changes in the adjacent hepatic cells, (4c) Intestine of negative control (unchallenged) chicken showing all intestinal coats within the normal morphological picture, (4d) liver of negative control (unchallenged) chicken showing normal hepatic parenchyma. (H\&E ×400) 


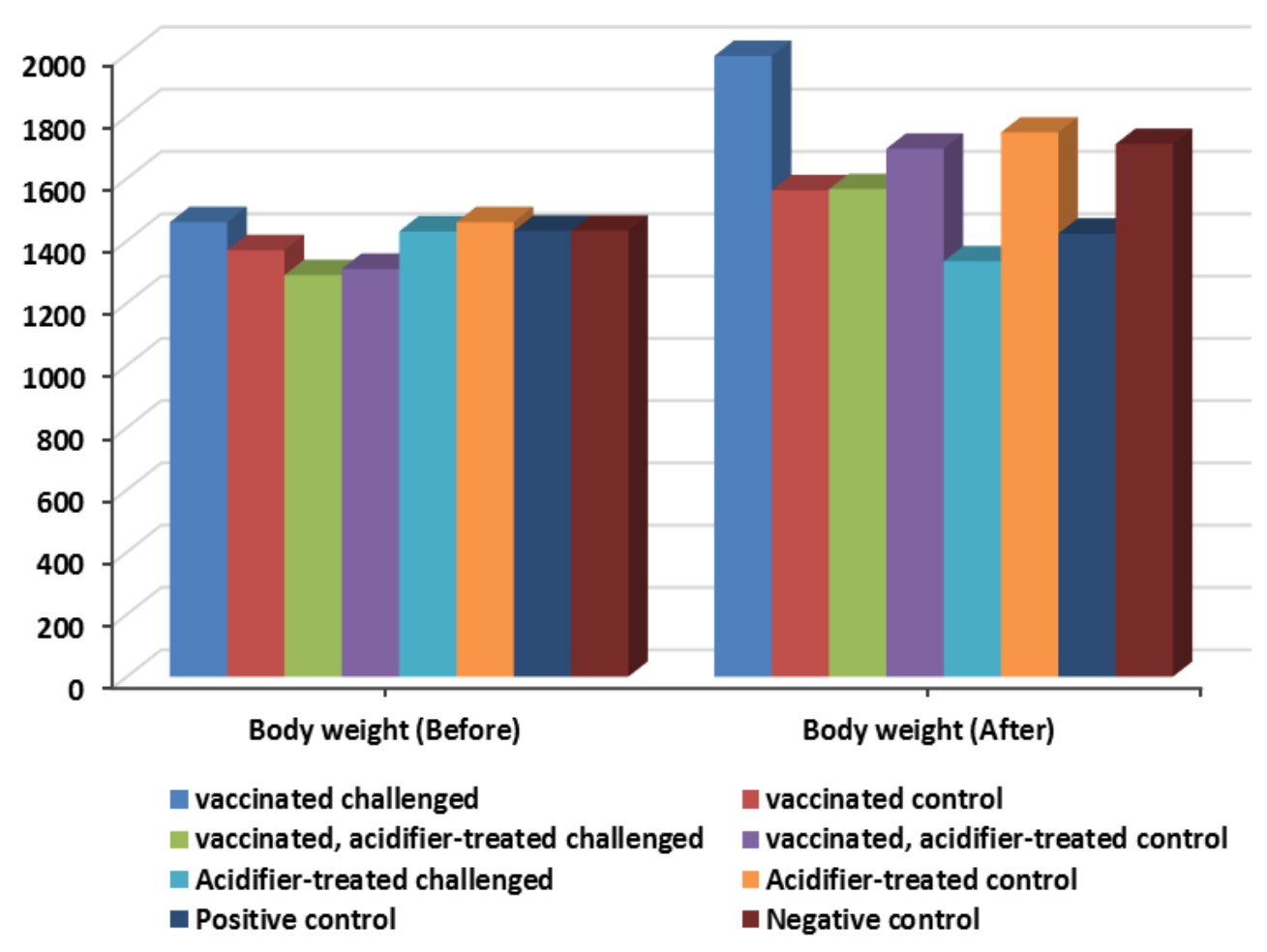

Figure 5. Changes in the average body weight (g) among different chicken groups (before and after challenge with toxigenic Clostridium perfringens culture) during the experiment.

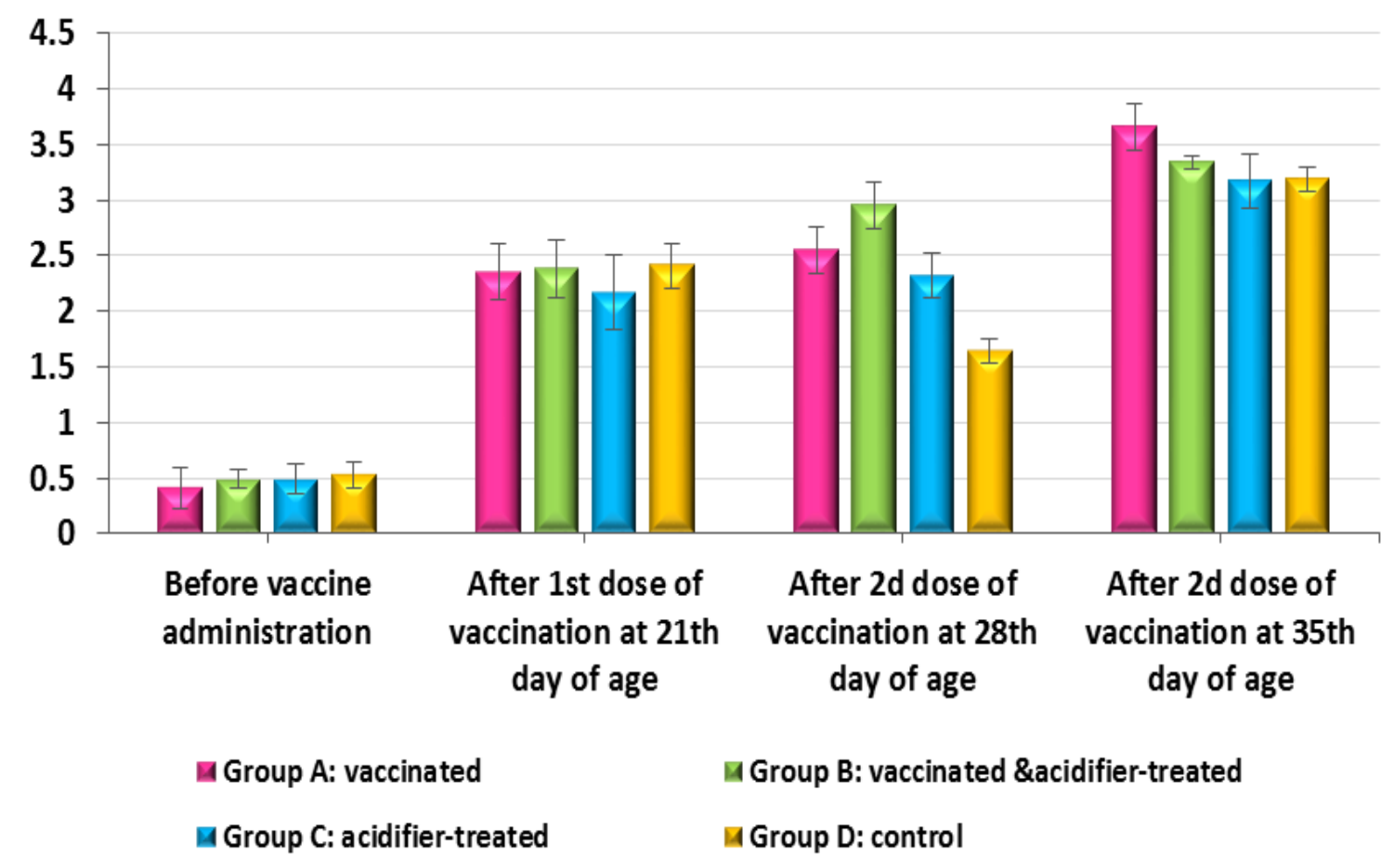

Figure 6. Titers of anti-alpha toxin IgY detected by ELISA in different chicken groups before challenge with toxigenic Clostridium perfringens culture. 


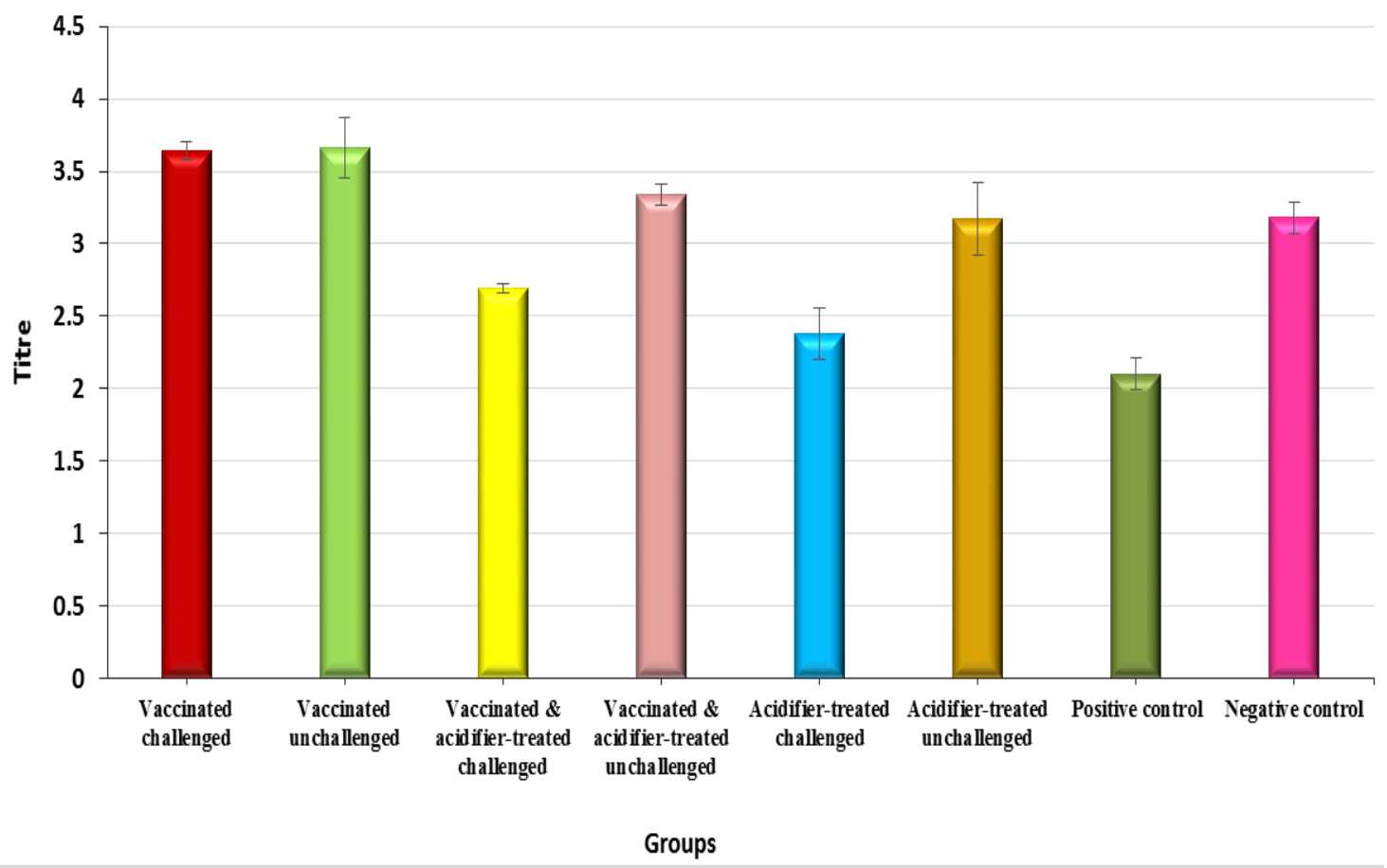

Figure 7. Comparison of anti-alpha toxin IgY detected by ELISA among different challenged (with toxigenic Clostridium perfringens culture) and non-challenged chicken groups at $35^{\text {th }}$ days of age.

\section{DISCUSSION}

In this study, birds were experimentally challenged by oral administration of freshly prepared whole C.perfringens culture with a bacterial concentration of $10^{9} \mathrm{CFU} / \mathrm{ml}$ and preformed toxin with MLD 1/80. In agreement with Shojadoost et al. (2012) who declared that it is preferable to experimentally induce $\mathrm{NE}$ using whole $C$. perfringens culture containing preformed toxin which initiates intestinal damage rather than waiting for the toxin to be produced by pathogenic $C$. perfringens strain in the intestine. Besides, the strain used for NE challenge was NetB-negative C.perfringens isolate, thus, this study suggested that the NetB is not sufficient alone for disease development and its critical role in NE occurrence depends on further factors. This study is consistent with Martin and Smyth (2009) who declared that NetB is not an essential factor for $\mathrm{NE}$ induction in all cases, but inconsistent with Rood et al. (2016) who declared that $\mathrm{NetB}$ toxin is an important virulence factor in $\mathrm{NE}$ occurrence.

There were no marked clinical signs detected in the experimental study even in the positive control. The challenged birds showed the subclinical form of NE in agreement with Wilson et al. (2005); Olkowski et al. (2008) and Pedersen et al. (2008) who ensured that NE experimental challenge without combination of any nutritional factors, Eimeria co-infection or IBD vaccines, resulted in the development of a subclinical form of the disease with no clinical signs. The reason for exclusion of any predisposing factors from this study was interpreted by Shojadoost et al. (2012) who stated that NE reproduction without the aid of any predisposing factors is an important element in case of testing a vaccine or a specific drug against $\mathrm{NE}$ to avoid the induction of extremely severe disease. No apparently macroscopic lesions in all unchallenged broilers (lesion score $=0$ ) in agreement with $\mathrm{Du}$ et al. (2016) and $\mathrm{Li}$ et al. (2018) indicating no exogenous infection affecting the experiment's results. Thin and friable intestinal wall in all challenged subgroups either vaccinated, Nutri Lac-IGA or both of them (lesion score =1) and lesions in positive control varying from thin and friable intestine (lesion score $=1$ ) to ulceration (lesion score $=2$ ) with severely enlarged and congested liver with or without necrosis. Thinning and friability of intestinal wall with gas ballooning at some intestinal parts were previously investigated by Broussard et al. (1986) and Kaldhusdal and Hofshagen (1992) who declared that typical subclinical form of NE contained ulceration with discolored material adhering to the mucosa and Løvland and Kaldhusdal (1999) who detected severely enlarged 
livers sometimes with pale necrotic foci in subclinical NE cases.

The moderate total mortality (20\%) among positive control subgroups, along with the low lesion scores observed in the challenged birds was indicative of the established subclinical NE in chickens during this study. Similar results were obtained by $\mathrm{Li}$ et al. (2018) who orally challenged broiler chickens with $C$. Perfringens culture $\left(2 \times 10^{8} \mathrm{CFU} / \mathrm{ml}, 1.0 \mathrm{ml} / \mathrm{bird}\right)$ and reported that challenged birds had $20 \%$ mortality, while no mortalities were recorded in the control group.

There was variation in protection due to vaccination and/or Nutri-Lac treatment against NE histopathological detrimental changes with the highest degree of protection in vaccinated \& Nutrilac IGA-treated subgroup and the lowest one in Nutrilac IGA-treated subgroup. No significant histopathological findings could be detected in euthanized birds except in positive control subgroup which showed revealed diffuse coagulative necrosis containing bacterial colonies and inflammatory cells in the superficial mucosa with extension to the deeper mucosa. Besides, the presence of necrotic debris and inflammatory cells in the lumen was common. In agreement with Olkowski et al. (2006) who discussed the histopathological changes accompanied by NE has including hyperemic mucosa which was infiltrated with numerous inflammatory cells mainly heterophiles and Van Hoek (2013) who found large and gram-positive rod-shaped bacilli attached to submucosa after the sloughing of necrotic mucosa.

The statistical results revealed that the $\mathrm{BW}$ of broilers in all subgroups did not statistically differ ( $P>0.05)$ before the experimental challenge. As all broiler chickens were reared under the same managemental conditions. Also, there was an obvious increase in weight gain among all unchallenged birds during the period between $1^{\text {st }}$ and $2^{\text {nd }}$ BW measurement (vaccinated \& Nutrilac IGA-treated $\mathrm{P}<0.01$, Nutrilac IGA-treated and negative controls $\mathrm{P}<0.05$ ), even if it was neglected in vaccinated control sub-group $(P>0.05)$ during the experiment, which was highly revealing of the absence of any exogenous infection which could badly affect the growth performance of tested broilers during the experiment. There was an insignificant decrease in BW after challenge in the positive control subgroup ( $\mathrm{P}>0.05)$, in agreement with other investigators who recorded the neglected decrease in BW after the subclinical infection of NE (Pedersen et al., 2008; Du et al., 2016; Fasina et al., 2016; Fasina and Lillehoj, 2019). Although other investigators declared a significant decrease in $\mathrm{BW}$ in infected birds compared with uninfected birds (Chalmers et al., 2007; Mikkelsen et al., 2009; Liu et al., 2010).

The results also showed a marked elevation in BW gain after challenge in vaccinated $(\mathrm{P}<0.01)$ and vaccinated $\&$ Nutrilac IGA-treated subgroups $(\mathrm{P}<0.05)$ respectively. The effect of vaccine administration on $\mathrm{BW}$ gain was previously investigated by Jang et al. (2012) who suggested that vaccination with C.perfringens recombinant proteins, particularly NetB toxin or perfringolysin PFO improved BW gain and protective immunity against experimental NE induction in broilers. Dietary supplementation with Nutrilac IGA (immunostimulant contains formic acid 10\% and lactic acid $10 \%$ ) had an overt impact on growth performance only among unchallenged birds in agreement with Rosen (2007); Abdel-Fattah et al. (2008); Dizaji et al. (2012) and Hedayati et al. (2013) who administrated several organic acids in broilers as growth promoter and immunomodulator. Besides, early access to Nutrilac IGA showed a significant elevation in BW in vaccinated \& Nutrilac IGA-treated challenged sub-group $(\mathrm{P}<0.05)$. Although Nutrilac IGA administration significantly elevated BW in unchallenged birds either when it administrated alone $(\mathrm{P}<0.05)$ or concurrently with vaccine $(\mathrm{P}<0.01)$, it failed to improve weight gain in challenged birds when it administrated alone. Closely-related results obtained by Ao et al. (2012) who indicated that early dietary supplementation of MOS and/or organic acids improved the intestinal absorption, increased the villus height/crypt depth ratio and enhanced the chicken growth performance before $C$. perfringens challenge. However, neither of these feed additives gave the broilers the same degree of protection against $C$. perfringens challenge as any antibiotic did and failed to prevent the $\mathrm{NE}$ consequences as high lesion scores and low weight gain.

Vaccination can provide a valuable tool for the prevention of NE under field conditions (Keyburn et al., 2013). OneWay ANOVA results showed that after challenge, the vaccinated challenged birds either with or without Nutrilac IGA treatment, had higher antibody titer more than unvaccinated challenged birds either Nutrilac IGAtreated or positive control. This result came in contact with Cooper et al. (2009) who declared that anti-alpha toxin $\operatorname{IgY}$ titer in vaccinated chickens was 5-fold greater than that in non-vaccinated chickens. Moreover, anti-alpha toxin IgY titer elevated after challenge in vaccinated birds and was 15 -fold higher than that in non-vaccinated birds. These results suggested that alpha toxin can produce an effective immune response in addition to its role in pathogenesis. SNT results revealed that the prepared 
toxoid gave protective mean $\operatorname{IgY}$ titer after $2^{\text {nd }}$ dose of vaccination at $28^{\text {th }}$ day and $35^{\text {th }}$ day of age higher than the mean $\operatorname{IgY}$ titer after $1^{\text {st }}$ dose of vaccination at $21^{\text {st }}$ day of age in both vaccinated and vaccinated \&Nutrilac IGAtreated groups. ELISA readings revealed the same result as a significant elevation in the $\operatorname{IgY}$ titer after the $2^{\text {nd }}$ dose of vaccination at $28^{\text {th }}$ day and $35^{\text {th }}$ day of broilers comparing to the IgY titer after the $1^{\text {st }}$ dose of vaccination at $21^{\text {st }}$ day of broiler age also in both vaccinated and vaccinated Nutrilac IGA-treated group respectively. These results ensured the significance of booster dose of vaccination in immune enhancement for a longer period and multiple vaccination regimens can markedly reduce $\mathrm{NE}$ lesions in challenged birds in agreement with other reports (Kulkarni et al., 2007; Cooper et al., 2009; Lanckriet et al., 2010b; Saleh et al., 2011; Jang et al., 2012). SNT results also showed the measured mean anti alpha toxin in all vaccinated groups exceeded the international standard $(0.5$ $\mathrm{IU} / \mathrm{ml}$ ) which was determined by European pharmacopeia, (2001) while low (2 IU/ml) or no (0 IU/ml) mean antialpha titer could be detected in both Nutrilac IGA-treated control and challenged subgroups respectively. Generally, vaccinated birds were more resistant to experimental challenge and the NE induction compared with the unvaccinated tested broilers. All vaccinated chickens could produce anti-alpha toxin antibodies in serum $(\operatorname{IgY})$ and intestine (IgY and $\operatorname{IgA}$ ), regardless of their degree of immune protection according to Lee et al. (2011).

This study used vaccine preparation depending on alpha toxin for immunization against induced NE (alpha toxin which converted to toxoid), and that contradicted several investigators who declared that there were antigens other than alpha toxin play a critical role in protection against NE including NetB toxin (Jang et al., 2012; Lee et al., 2012 and Keyburn et al., 2013). In a study made by Kulkarni et al. (2007) comparing the degree of immunization among different immunogenic proteins secreted by virulent $C$.perfringens including alpha protein, hypothetical protein, pyruvate ferredoxin oxidoreductase, glyceraldehyde-3-phosphate dehydrogenase, and fructose 1,6-biphosphate aldolase. The study found that all proteins give protection against challenge. ELISA results indicated a high titer of antibody could be detected in unchallenged Nutrilac IGA-treated birds either when it administrated alone or with the toxoid comparing with challenged Nutrilac IGA-treated birds either when it administrated alone or with the toxoid. Moreover, challenged Nutrilac IGA-treated subgroup had anti-alpha titer higher than the positive control but this difference was too little to be neglected $(\mathrm{P}>0.05)$. The same indication can be concluded from SNT results as the mean anti-alpha titer in challenged Nutrilac IGA-treated subgroup was (0 IU/ml) compared with unchallenged $(2 \mathrm{IU} / \mathrm{ml})$. This study closely related to a study done by Ao et al. (2012) who found stronger immune response in birds fed on organic acidsupplemented diet but none of the supplemented feed additives could achieve full protection against $\mathrm{NE}$ challenge. Higher immune response could also be detected in Nutrilac IGA-treated birds in this study but under C.perfringens challenge, it failed to fully protect challenged birds alone. On the other hand, Combination of vaccine and Nutrilac IGA (as immunostimulant) in this study gave promising results in NE control in agreement with Lohakare et al. (2005) who achieved better results in post-vaccine immune response when organic acids were supplemented in poultry diets

This study did not apply an experimental model depending on birds' exposure to predisposing factors which considered as an aid for NE induction. As a result of this, the vaccination regimen was able to successfully protect the tested chickens, to some extent, from the disease development. In agreement with Zahoor et al. (2018) who concluded that the incidence of NE can be minimized up to some extent by minimal exposure of chickens to predisposing factors as well as vaccinating the birds with $C$. perfringens and/or its toxoids.

\section{CONCLUSION}

The present study demonstrated that Nutrilac IGA treatment alone could not control necrotic enteritis. Multiple vaccination regimen provides higher protection level against necrotic enteritis than single vaccination regimen. Vaccine accompanied by Nutrilac IGA was effective in the prevention of necrotic enteritis only when it was accompanied by the absence of predisposing factors of necrotic enteritis.

\section{DECLARATIONS}

\section{Acknowledgment}

The authors would like to acknowledge the Department of Anaerobe at Veterinary Serum and Vaccine Research Institute, Abbassia, Cairo, Egypt for logistic supports. 


\section{Authors' contributions}

S.S. Helal applied the practical part of experimental work and wrote the manuscript. H.F.Gouda made the statistical analysis for all results of the experiment and helped in the practical work. N.M. Khalaf prepared and evaluated toxoid, prepared the toxigenic culture and helped in experimental tests. R.I. Hamed helped in manuscript writing. A.A. Ali made the histopathological work. M.A. Lebdah designed the experiment and supervised the work.

\section{Competing interests}

The authors declare that they have no competing interests.

\section{REFERENCES}

Abdel-Fattah SA, El-Sanhoury MH, El-Mednay NM and Abdel-Azeem F (2008). Thyroid activity, some blood constituents, organs morphology and performance of broiler chicks fed supplemental organic acids. International Journal of Poultry Science, 7: 215-222. DOI: https://doi.org/10.3923/ijps.2008.215.222.

Ao Z, Kocher A and Choct M (2012). Effects of dietary additives and early feeding on performance, gut development and immune status of broiler chickens challenged with Clostridium perfringens. AsianAustralasian Journal of Animal Sciences, 25: 541-551. DOI: https://doi.org/10.5713/ajas.2011.11378.

British Veterinary Pharmacopoeia (2007). Volume 5, The pharmaceutical press, London.

Broussard CT, Hofacre CL, Page RK and Fletcher OJ (1986). Necrotic enteritis in cage-reared commercial layer pullets. Avian Diseases, 30: 617-619. Available at: https://www.jstor.org/stable/1590433.

Casewell M, Friis C, Marco E, McMullin P and Phillips I (2003). The European ban on growth-promoting antibiotics and emerging consequences for human and animal health. Journal of Antimicrobial Chemotherapy, 52: 159-161. DOI: https://doi.org/10.1093/jac/dkg313.

Chalmers G, Bruce HL, Toole DL, Barnum DA and Boerlin P (2007). Necrotic enteritis potential in a model system using Clostridium perfringens isolated from field outbreaks. Avian Diseases, 51: 834-839. DOI: https://doi.org/10.1637/7959-022807-REGR.1.

Cooper KK, Songer JG and Uzal FA (2013). Diagnosing Clostridial enteric disease in poultry. Journal of veterinary diagnostic investigation : official publication of the American Association of Veterinary Laboratory Diagnosticians, 25: 314-327. DOI: https://doi.org/10.1177/1040638713483468.

Cooper KK, Trinh HT and Songer JG (2009). Immunization with recombinant alpha toxin partially protects broiler chicks against experimental challenge with Clostridium perfringens. Veterinary Microbiology, 133: 92-97. DOI: https://doi.org/10.1016/j.vetmic.2008.06.001.
Dizaji BR, Hejazi S and Zakeri A (2012). Effects of dietary supplementations of prebiotics, probiotics, synbiotics and acidifiers on growth performance and organs weights of broiler chicken. European Journal of Experimental Biology, 2: 2125-2129. Available at: http://www.pelagiaresearchlibrary.com

Du E, Wang W, Gan L, Li Z, Guo S and Guo Y (2016). Effects of thymol and carvacrol supplementation on intestinal integrity and immune responses of broiler chickens challenged with Clostridium perfringens. Journal of Animal Science and Biotechnology, 7: 19. DOI: https://doi.org/10.1186/s40104-016-0079-7.

European pharmacopeia (1997). Veterinary vaccine, $3^{\text {rd }}$ edition. Council of Europe, Strasburg.

European pharmacopeia (2001). Clostridium perfringens vaccine for veterinary use, $3^{\text {rd }}$ edition. Council of Europe, Strasburg, pp. 649-651.

Fasina YO and Lillehoj HS (2019). Characterization of intestinal immune response to Clostridium perfringens infection in broiler chickens. Poultry Science, 98: 188-198. DOI: https://doi.org/10.3382/ps/pey390.

Fasina YO, Newman MM, Stough JM and Liles MR (2016) . Effect of Clostridium perfringens infection and antibiotic administration on microbiota in the small intestine of broiler chickens. Poultry Science, 95: 247-260. DOI: https://doi.org/10.3382/ps/pev329.

Gadalla MS, Farrag I and Sharaf D (1974). Effect of growth requirement on the improvement of Clostridia vaccine. Journal of the Egyptian Veterinary Medical Association, 34: 19-28.

Hedayati M, Manafi M, Yari M and Vafaei P (2013). Effects of supplementing diets with an acidifier on performance parameters and visceral organ weights of broilers. European Journal of Zoological Research, 2: 49-55. Available at: https://www.scholarsresearchlibrary.com.

Helal SS, Khalaf NM, El menisy AA and Lebdah MA (2019). Clostridium perfringens type A causing necrotic enteritis outbreaks among chickens in Egypt. Zagazig Veterinary Journal, 47: 398-407. DOI: https://doi.org/10.21608/ZVJZ.2019.14139.1055.

Jang SI, Lillehoj HS, Lee SH, Lee KW, Lillehoj EP, Hong YH, An DJ, Jeong W, Chun JE, Bertrand F, Dupuis L, Deville S and Arous JB (2012). Vaccination with Clostridium perfringens recombinant proteins in combination with Montanide ${ }^{\mathrm{TM}}$ ISA 71 VG adjuvant increases protection against experimental necrotic enteritis in commercial broiler chickens. Vaccine, 30: 5401-5406. DOI: https://doi.org/10.1016/j.vaccine.2012.06.007.

Jerzsele A, Szeker K, Csizinszky R, Gere E, Jakab C, Mallo JJ and Galfi P (2012). Efficacy of protected sodium butyrate, a protected blend of essential oils, their combination, and Bacillus amyloliquefaciens spore suspension against artificially induced necrotic enteritis in broilers. Poultry Science, 91: 837-843. DOI: https://doi.org/10.3382/ps.2011-01853.

Kaldhusdal M and Hofshagen M (1992). Barley inclusion and avoparcin supplementation in broiler diets: 2. Clinical, pathological, and bacteriological findings in a mild form of necrotic enteritis. Poultry Science, 71: 1145-1153. DOI: https://doi.org/10.3382/ps.0711145. 
Helal et al., 2020

Keyburn AL, Portela RW, Ford ME, Bannam TL, Yan XX, Rood JI and Moore RJ (2013). Maternal immunization with vaccines containing recombinant NetB toxin partially protects progeny chickens from necrotic enteritis. Veterinary Research, 44: $108 . \quad$ DOI: https://doi.org/10.1186/1297-9716-44-108.

Keyburn AL, Boyce JD, Vaz P, Bannam TL, Ford ME, Parker D, Di Rubbo A, Rood JI and Moore RJ (2008). NetB, a new toxin that is associated with avian necrotic enteritis caused by Clostridium perfringens. PLOS Pathogens, $\quad 4$ : $\quad$ e26. https://doi.org/10.1371/journal.ppat.0040026.

Kulkarni RR, Parreira VR, Sharif S and Prescott JF (2007). Immunization of broiler chickens against Clostridium perfringens -induced necrotic enteritis. Clinical and Vaccine Immunology, 14: 1070-1077. DOI: https://doi.org/10.1128/CVI.00162-07.

Lanckriet A, Timbermont L, Eeckhaut V, Haesebrouck F, Ducatelle R and Van Immerseel F (2010b). Variable protection after vaccination of broiler chickens against necrotic enteritis using supernatants of different Clostridium perfringens strains. Vaccine, 28: 5920-5923. DOI: https://doi.org/10.1016/j.vaccine.2010.06.035.

Lanckriet A, Timbermont L, De Gussem M, Marien M, Vancraeynest D, Haesebrouck F, Ducatelle R and Van Immerseel F (2010a). The effect of commonly used anticoccidials and antibiotics in a subclinical necrotic enteritis model. Avian Pathology, 39: 63-68. DOI: https://doi.org/10.1080/03079450903505771.

Lee KW, Lillehoj HS, Park MS, Jang SI, Ritter GD, Hong YH, Jeong W, Jeoung HY, An DJ and Lillehoj EP (2012). Clostridium perfringens $\alpha$-Toxin and NetB toxin antibodies and their possible role in protection against necrotic enteritis and gangrenous dermatitis in broiler chickens. Avian Diseases, 56: 230-233. DOI: https://doi.org/10.1637/9847-070711-ResNote.1.

Lee KW, Lillehoj HS, Jeong W, Jeoung HY and An DJ (2011). Avian necrotic enteritis: Experimental models, host immunity, pathogenesis, risk factors, and vaccine development. Poultry Science, 90: 1381-1390. DOI: https://doi.org/10.3382/ps.2010-01319.

Li Z, Wang W, Liu D and Guo Y (2018). Effects of Lactobacillus acidophilus on the growth performance and intestinal health of broilers challenged with Clostridium perfringens. Journal of Animal Science and Biotechnology, 9: 25. DOI: https://doi.org/10.1186/s40104-018-0243-3.

Liu D, Guo Y, Wang Z and Yuan J (2010). Exogenous lysozyme influences Clostridium perfringens colonization and intestinal barrier function in broiler chickens. Avian Pathology, 39: 17-24. 3O https://doi.org/10.1080/03079450903447404.

Lohakare JD, Ryu MH, Hahn TW, Lee JK and Chae BJ (2005). Effects of Supplemental Ascorbic Acid on the Performance and Immunity of Commercial Broilers. The Journal of Applied Poultry Research, 14: 10-19. DOI: https://doi.org/10.1093/japr/14.1.10.

Lovland A and Kaldhusdal M (2001). Severely impaired production performance in broiler flocks with high incidence of Clostridium perfringens-associated hepatitis. Avian Pathology, 30: 73-81. DOI: https://doi.org/10.1080/03079450020023230.
Løvland A and Kaldhusdal M (1999). Liver lesions seen at slaughter as an indicator of necrotic enteritis in broiler flocks. FEMS Immunology \& Medical Microbiology, 24: 345-351. DOI: https://doi.org/10.1111/j.1574695X.1999.tb01304.x.

Martin TG and Smyth JA (2009). Prevalence of netB among some clinical isolates of Clostridium perfringens from animals in the United States. Veterinary Microbiology, 136: 202-205.

DOI: https://doi.org/10.1016/j.vetmic.2008.10.026.

Mikkelsen LL, Vidanarachchi JK, Olnood CG, Bao YM, Selle $\mathrm{PH}$ and Choct M (2009). Effect of potassium diformate on growth performance and gut microbiota in broiler chickens challenged with necrotic enteritis. British Poultry Science, 50: 66-75.

DOI: https://doi.org/10.1080/00071660802613252.

Mot D, Timbermont L, Delezie E, Haesebrouck F, Ducatelle $\mathrm{R}$ and Van Immerseel F (2013). Day-of-hatch vaccination is not protective against necrotic enteritis in broiler chickens. Avian Pathology, 42: 179-184. DOI: https://doi.org/10.1080/03079457.2013.778955.

Mot D, Timbermont L, Haesebrouck F, Ducatelle R and Van Immerseel F (2014). Progress and problems in vaccination against necrotic enteritis in broiler chickens. Avian Pathology, 43: 290-300. DOI: https://doi.org/10.1080/03079457.2014.939942.

Olkowski AA, Wojnarowicz C, Chirino-Trejo M, Laarveld B and Sawicki G (2008). Sub-clinical necrotic enteritis in broiler chickens: Novel etiological consideration based on ultra-structural and molecular changes in the intestinal tissue. Research in Veterinary Science, 85: 543-553. DOI: https://doi.org/10.1016/j.rvsc.2008.02.007.

Olkowski AA, Wojnarowicz C, Chirino-Trejo M and Drew MD (2006). Responses of broiler chickens orally challenged with Clostridium perfringens isolated from field cases of necrotic enteritis. Research in Veterinary Science, 81: 99108. DOI: https://doi.org/10.1016/j.rvsc.2005.10.006.

Pedersen K, Bjerrum L, Eske Heuer O, Lo Fo Wong DMA and Nauerby B (2008). Reproducible infection model for Clostridium perfringens in broiler chickens. Avian Diseases, 52: 34-39. DOI: https://doi.org/10.1637/7955-022307-Reg.

Prescott JF, Sivendra R and Barnum DA (1978). The use of bacitracin in the prevention and treatment of experimentally-induced necrotic enteritis in the chicken. The Canadian Veterinary Journal, 19: 181-183. PMID: 698898; PMCID: PMC1789416.

Rood JI, Keyburn AL and Moore RJ (2016). NetB and necrotic enteritis: the hole movable story. Avian Pathology, 45: 295-301. DOI: https://doi.org/10.1080/03079457.2016.1158781.

Rosen GD (2007). Holo-analysis of the efficacy of Bio-Mos® in broiler nutrition. British Poultry Science, 48: 21-26. DOI: https://doi.org/10.1080/00071660601050755.

Saleh N, Fathalla S I, Nabil R and Mosaad AA (2011). Clinicopathological and immunological studies on toxoids vaccine as a successful alternative in controlling clostridial infection in broilers. Anaerobe, 17: 426-430. DOI: https://doi.org/10.1016/j.anaerobe.2011.04.019.

Shojadoost B, Vince AR and Prescott JF (2012). The successful experimental induction of necrotic enteritis in chickens by 
Clostridium perfringens: a critical review. Veterinary Research, 43: 74. DOI: https://doi.org/10.1186/1297-971643-74.

Skinner JT, Bauer S, Young V, Pauling G and Wilson J (2010). An economic analysis of the impact of subclinical (mild) necrotic enteritis in broiler chickens. Avian Diseases, 54: 1237-1240. DOI: https://doi.org/10.1637/9399-052110Reg.1.

Timbermont L, Lanckriet A, Dewulf J, Nollet N, Schwarzer $\mathrm{K}$, Haesebrouck F, Ducatelle $\mathrm{R}$ and Van Immerseel $\mathrm{F}$ (2010). Control of Clostridium perfringens-induced necrotic enteritis in broilers by target-released butyric acid, fatty acids and essential oils. Avian Pathology, 39: 117-121. DOI: https://doi.org/10.1080/03079451003610586.

Timbermont L, Haesebrouck F, Ducatelle R and Van Immerseel F (2011). Necrotic enteritis in broilers: an updated review on the pathogenesis. Avian Pathology, 40: 341-347. DOI: https://doi.org/10.1080/03079457.2011.590967.

Vaarst M, Steenfeldt S and Horsted K (2015). Sustainable development perspectives of poultry production. World's Poultry Science Journal, 71: 609-620. DOI: https://doi.org/10.1017/S0043933915002433.
Van Hoek ML (2013). Biofilms. Virulence, 4: 833-846. DOI: https://doi.org/10.4161/viru.27023.

Van Immerseel F, Rood JI, Moore RJ and Titball RW (2009). Rethinking our understanding of the pathogenesis of necrotic enteritis in chickens. Trends in Microbiology, 17: 32-36. DOI: https://doi.org/10.1016/j.tim.2008.09.005.

Wilson J, Tice G, Brash ML and Hilaire SS (2005). Manifestations of Clostridium perfringens and related bacterial enteritides in broiler chickens. World's Poultry Science Journal, 61: 435-449. DOI: https://doi.org/10.1079/WPS200566.

Wood K R (1991). An alternative to the toxin neutralization assay in mice for the potency testing of the Clostridium tetani, Clostridium septicum, Clostridium novyi type B and Clostridium perfringens type D epsilon components of multivalent sheep vaccines. Biologicals: Journal of the International Association of Biological Standardization, 19: 281-286. DOI: https://doi.org/10.1016/S10451056(05)80016-8.

Zahoor, I, Ghayas, A and Basheer, A (2018). Genetics and genomics of susceptibility and immune response to necrotic enteritis in chicken: A review. Molecular Biology Reports, 45: 31-37. DOI: https://doi.org/10.1007/s11033-017-4138-8 